\title{
Correlações entre ruído ambiental em sala de aula e voz do professor
}

\author{
Correlations between classroom environmental noise and \\ teachers'voice
}

\author{
Rafaela Fernanda Guidini $^{1}$, Fabiana Bertoncello ${ }^{1}$, Sthella Zanchetta ${ }^{2}$, Maria Lúcia Suzigan Dragone ${ }^{3}$
}

\begin{abstract}
RESUMO
Objetivo: Identificar se existe correlação entre ruído ambiental no interior da sala de aula, intensidade da voz e presença de alteração vocal em professores. Métodos: Foi realizada medição do ruído ambiental em dez salas de escolas municipais de ensino fundamental. A intensidade das vozes das professoras foi medida durante atividade de ensino. Amostras de vogal prolongada [é] e contagem de 1 a 20 emitidas pelas professoras foram analisadas utilizando escala GRBASI. Os resultados obtidos foram correlacionados. Resultados: A média de ruído ambiental sem a presença das crianças em sala de aula variou de 40 a $51 \mathrm{~dB}(\mathrm{~A})$ e com a presença das crianças de 45 a $65 \mathrm{~dB}(\mathrm{~A})$. Entre as professoras, houve 70\% de ocorrência de vozes alteradas no grau geral (G) e 90\% com tensão na voz (S), variando entre graus discreto e moderado. Constatou-se variação entre $52 \mathrm{~dB}(\mathrm{~A})$ e $68 \mathrm{~dB}(\mathrm{~A})$ na intensidade da voz das professoras, atingindo 7,48 dB(A) acima do nível do ruído ambiental. Houve correlação entre a intensidade vocal das professoras e ruído ambiental na presença das crianças durante a aula. Conclusão: Os níveis de ruído ambiental em sala de aula são altos e se correlacionam com o aumento da intensidade das vozes das professoras. Embora com alta ocorrência de vozes alteradas, não é possível correlacioná-las com o nível de ruído ambiental.
\end{abstract}

Descritores: Voz; Ruído; Docentes; Disfonia; Percepção auditiva

\section{INTRODUÇÃO}

A preocupação com o ambiente de trabalho e sua relação com a saúde não é recente. A poluição sonora vem se tornando um problema cada vez maior, exigindo ações e formas de controle para minimizar seus efeitos nocivos em todas as instâncias e para melhorar as condições de saúde da população.

A Associação Brasileira de Normas Técnicas (ABNT), na Norma Brasileira Registrada NBR $10152^{(1)}$, prevê como aceitável para salas de aula um ruído ambiente de 40 a $50 \mathrm{~dB}(\mathrm{~A})$, sendo que valores acima desta faixa são considerados nocivos à saúde ${ }^{(2)}$. Os ruídos intensos dificultam a comunicação verbal,

Trabalho realizado no Curso de Fonoaudiologia, Centro Universitário de Araraquara - UNIARA - Araraquara (SP), Brasil.

Conflito de interesses: Não

(1) Curso de Fonoaudiologia, Centro Universitário de Araraquara - UNIARA

- Araraquara (SP), Brasil.

(2) Departamento de Oftalmologia, Otorrinolaringologia e Cirurgia de Cabeça e Pescoço, Faculdade de Medicina de Ribeirão Preto, Universidade de São Paulo - USP - Ribeirão Preto (SP), Brasil.

(3) Departamento de Ciências Exatas e Naturais e Departamento de Ciências Humanas, Centro Universitário de Araraquara - UNIARA - Araraquara (SP), Brasil.

Endereço para correspondência: Rafaela Fernanda Guidini. R. João Ortigosa, 413, COHAB, Igaraçu do Tietê (SP), Brasil, CEP: 17350-000. E-mail: rafaguidini@hotmail.com

Recebido em: 15/2/2011; Aceito em: 2/8/2012 acarretando o aumento da tensão psicológica e diminuição do nível de atenção ${ }^{(3)}$.

Nas escolas de ensino infantil, o ruído ambiental está presente de diversas formas: externos aos prédios das instituições provindos das ruas que as cercam; externos somente às salas de aula provindos dos pátios, corredores, salas vizinhas, campainhas, manutenção dos prédios; internos à sala de aula, decorrentes da fala das crianças e de ruídos de equipamentos como ventiladores. Em sala de aula o aluno recebe dois diferentes estímulos sonoros: a voz do professor, que deveria ser o principal foco de atenção do aluno; e o ruído ambiental, considerado como sinal competitivo que deveria ser negligenciado para a mensagem principal não se tornar distorcida ${ }^{(4)}$. O ruído interno à sala de aula é mais perceptível aos professores e alunos que os externos, notados aleatoriamente ${ }^{(5)}$. Em condições de acústica desfavorável, onde a intensidade de ruído mascara a voz do professor, o aluno terá dificuldade em compreender a mensagem ${ }^{(6)} \mathrm{o}$ que acarreta prejuízo no processo de ensino e aprendizagem e, além disso, pode ainda gerar estresse ao professor.

Ambientes ruidosos ocasionam falas em intensidade mais forte e a demanda contínua desse processo pode gerar desgastes nas estruturas de fonação e produzir, com o decorrer do tempo, alterações vocais. Tais alterações variam quanto ao grau de rouquidão e a presença ou não de lesões na mucosa da prega vocal. Neste contexto, o ambiente de trabalho do professor pode ser considerado inadequado ${ }^{(7)}$, pois além do ruído existem outros fatores desencadeantes de tensões inerentes ao exercício 
profissional $^{(8,9)}$. Entre tais fatores, podem ser identificados aqueles provindos da falta de informação sobre como produzir a fala com funcionalidade ideal para as diferentes tarefas do ensino, e os hábitos de vida desenvolvidos sócio-culturalmente.

Recentemente, um estudo brasileiro apontou que $63 \%$ dos professores referem que a presença de rouquidão é uma interferente negativa à comunicação ${ }^{(10)}$. Em outra pesquisa, $\mathrm{o}$ excesso de ruído foi citado pelos professores como causa de competição sonora e de esforço vocal ${ }^{(11)}$. A literatura aponta alta ocorrência de alterações vocais entre professores ${ }^{(12-17)}$, o que dificulta os procedimentos de interação em sala de aula e, consequentemente, prejudica a manutenção da atenção do aluno e sua participação ativa no processo de aprendizagem ${ }^{(18-21)}$, além de gerar estresse emocional ao professor ${ }^{(22)}$.

Nestas condições, o cansaço vocal do professor e os sinais de esforço vocal aparecem como fatores de risco para o desenvolvimento de alterações de $\mathrm{voz}^{(23)}$. Há referências de que a intensidade da voz do professor se eleva de 10 a $30 \mathrm{~dB}(\mathrm{~A})$ acima da intensidade dos ruídos ambientais ${ }^{(5,24)}$. No entanto, mesmo com a constatação de ruído ambiental intenso, com média de $72,7 \mathrm{~dB}(\mathrm{~A})$ e variando entre $56,1 \mathrm{~dB}(\mathrm{~A})$ e $94,1 \mathrm{~dB}(\mathrm{~A})^{(16,25)}$, não foi possível encontrar associações deste fator com a presença de disfonia em um grupo de educadores infantis da cidade de São Paulo ${ }^{(16)}$. Desse modo, nem sempre o ruído em sala de aula pode ser relacionado às dificuldades nos processos de aprendizagem ${ }^{(5)}$. Esta informação reforça o cuidado para não generalizar a correlação entre presença de ruído elevado e de alteração vocal, pois existem diferenças individuais na regência das reações do comportamento vocal em resposta a esta condição, conforme foram registradas entre professores de pré-escola na Suécia ${ }^{(26)}$.

$\mathrm{Na}$ presença de alterações vocais no professor, as consequências podem ser amplas e envolver o próprio sujeito e a sua qualidade de vida, gerando redução de atividades ou interações sociais, dificuldades em sua comunicação e vida social, problemas emocionais e psicológicos, além da perda de dias de trabalho. O absenteísmo é negativo no âmbito da organização do trabalho e conduz a dificuldades na aprendizagem dos alunos, prejuízos econômicos para os profissionais e para as instituições de ensino ${ }^{(9)}$.

Desse modo, a investigação do ambiente de trabalho do docente torna-se importante, pois possibilita a identificação de fatores predisponentes para a instalação de alterações vocais em professores. Entre estes fatores, é possível avaliar os níveis de pressão sonora/ruído produzidos no período em que o educador desenvolve suas atividades, e analisar a associação entre a exposição sonora e as possíveis alterações vocais ${ }^{(8)}$.

Nesse contexto, este estudo teve por objetivo investigar as correlações relações entre ruído ambiental na sala de aula, a intensidade da voz e a presença de alteração vocal de professores de primeiro ano do ensino fundamental.

\section{MÉTODOS}

O desenvolvimento da pesquisa ocorreu em instituições da rede municipal de ensino de uma cidade do interior do estado de São Paulo com prévia autorização formal de seus gestores e com consentimento livre e esclarecido das professoras par- ticipantes. O projeto foi aprovado pelo Comitê de Ética em Pesquisa do Centro Universitário de Araraquara (UNIARA), protocolo 809/08.

Optou-se por estudar o ruído ambiental em salas de primeiro ano do ensino fundamental. Essa escolha baseou-se no fato de ser esse um ano importante para o aprendizado formal, por causa do processo de alfabetização nele contido. Sabe-se também que nesse processo há uma grande demanda de uso da voz por parte dos professores, e que na presença de ruído ambiental ou de professores com vozes alteradas podem ocorrer falhas relevantes no processo como um todo.

O estudo foi realizado em dez salas de aula de primeiro ano do ensino fundamental da cidade e, portanto, contou com a participação de dez professoras. A maioria das salas localizava-se no perímetro urbano, em bairros afastados do centro da cidade, em construção térrea, sendo que apenas três escolas tinham mais de um andar. A movimentação de carros nas ruas próximas variou entre as escolas. Todos os professores eram do gênero feminino, com média de idade de 40 anos. As pesquisadoras realizaram observações nos locais durante a coleta de dados, relacionadas ao ambiente físico da sala de aula, ao número de alunos e ao comportamento vocal das professoras, utilizando um mesmo padrão para todas as escolas (Quadro 1).

\section{Procedimento para coleta e análise do nível de intensidade sonora do ruído da sala de aula}

A pesquisa do nível de ruído nas salas de aula foi baseada nas recomendações das Normas Nacionais NBR $10.151^{(27)} \mathrm{e}$ NBR $10.152^{(1)}$.

Utilizou-se instrumento da marca Instrutherm ${ }^{\circledR}$, modelo Sound Level Meter (SL - 4011), devidamente calibrado. Foram utilizados: circuito de ponderação - "A", circuito de resposta - "lenta - SLOW", e faixa de medição entre 50 a 100 $\mathrm{dB}(\mathrm{A})$. A média do nível de pressão sonora (NPS) de ruído foi realizada a partir de duas avaliações em cada um de três pontos específicos selecionados na sala de aula, totalizando seis medições em cada sala. O medidor do nível de pressão sonora ficava sempre voltado para o centro da sala a um metro do chão e a um metro das paredes, com objetivo de evitar as ondas estacionárias, sendo um ponto próximo à lousa, outro próximo às janelas e o último próximo à porta da sala. Para cada ponto, foram registradas as intensidades mínimas, máximas e aquelas com variação maior ou igual a $5 \mathrm{~dB}(\mathrm{~A})$, durante um período de cinco minutos. As medições ocorreram em duas situações: com as salas sem alunos antes do início da aula, e no momento da aula com os alunos, na presença do professor em atividade didática que não fosse aula expositiva. Ressalta-se que o tempo de permanência da pesquisadora em sala de aula foi maior que o da coleta permitindo que alunos e professora se acostumassem com essa variável, com objetivo de atenuar esse interferente na rotina de cada uma das salas.

\section{Procedimento para coleta do nível de pressão sonora das vozes das professoras}

Optou-se por mensurar a intensidade vocal das professoras durante um minuto de aula expositiva. A determinação deste 
Quadro 1. Caracterização da amostra

\begin{tabular}{|lcccccl|}
\hline Sala & $\begin{array}{c}\text { Porta voltada } \\
\text { para: }\end{array}$ & $\begin{array}{c}\text { Janelas } \\
\text { voltadas para: }\end{array}$ & $\begin{array}{c}\text { Ruído } \\
\text { externo }\end{array}$ & Ventilador & nº alunos & Comportamento vocal das professoras \\
\hline 1 (térrea) & Outras salas & Rua & Pouco & Ruidoso & 12 & $\begin{array}{l}\text { Procurava não gritar, às vezes gritava por } \\
\text { causa da conversa dos alunos }\end{array}$ \\
\hline 2 (térrea) & Outras salas & Outras salas & Elevado & Ruidoso & 21 & $\begin{array}{l}\text { Era calma, porém apresentava tensão } \\
\text { fonatória }\end{array}$ \\
\hline 3 (piso superior) & Outras salas & Rua & Elevado & Ruidoso & 17 & $\begin{array}{l}\text { Falava baixo, mas, às vezes gritava por } \\
\text { causa da conversa dos alunos }\end{array}$ \\
\hline 4 (piso superior) & Outras salas & Rua & Pouco & Ruidoso & 23 & Não gritava muito e transmitia ser calma \\
\hline 5 (térrea) & Pátio & Rua & Elevado & Ruidoso & 28 & Falava alto e apresentava tensão fonatória \\
\hline 6 (térrea) & Terreno baldio & Outras salas & Pouco & Ruidoso & 14 & Falava alto e apresentava tensão fonatória \\
\hline 7 (térrea) & Pátio & $\begin{array}{c}\text { Rua e outras } \\
\text { salas }\end{array}$ & Pouco & Ruidoso & 26 & Apresentava tensão fonatória \\
\hline 8 (piso superior) & Corredor & $\begin{array}{c}\text { Rua e outras } \\
\text { salas }\end{array}$ & Pouco & Ruidoso & 24 & Falava baixo \\
\hline 9 (térrea) & Outras salas & Pátio & Elevado & Ruidoso & 18 & Falava alto \\
\hline 10 (térrea) & Biblioteca & Rua & Pouco & Ruidoso & 24 & Falava alto \\
\hline
\end{tabular}

momento de coleta permitiu que a medição ocorresse durante atividade de ensino e aprendizagem, ou seja, de transmissão direta do conhecimento. Sabe-se que esse tempo reduzido pode ter possibilitado a ocorrência de um viés na análise, uma vez que é possível ocorrer variabilidade das condições de fala do professor no decorrer do dia. Mesmo assim, as informações obtidas podem oferecer dados para contribuir com o conhecimento sobre o uso vocal do professor durante a aula.

O mesmo medidor (decibelímetro) foi utilizado para avaliar o nível de pressão sonora da voz do professor. O equipamento foi colocado a um metro de distância das professoras, em frente a elas, e a um metro do chão. Este posicionamento foi estabelecido para favorecer a fonte sonora principal - a voz do professor - em detrimento ao ruído do ambiente. Foram anotadas todas as variações do nível de pressão sonora (NPS) mínimas, máximas e aquelas com variação maior ou igual a $5 \mathrm{~dB}(\mathrm{~A})$.

\section{Procedimento para coleta e análise das amostras das vozes dos professores}

A amostra solicitada às professoras foi coletada em sala de aula sem a presença dos alunos, e constou da produção prolongada da vogal [é], e de contagem de números de 1 a 20, em voz habitual. Utilizou-se gravador digital Panasonic $®$, modelo RR-US 450, com microfone embutido, posicionado a $10 \mathrm{~cm}$ da boca e em ângulo agudo. A escolha do modelo por um gravador digital de qualidade, porém não profissional, ocorreu pela praticidade segundo as condições de coleta. Além disso, ao ser posicionado adequadamente, esse equipamento produz uma gravação com poucas distorções, apesar dos riscos de exposição aos interferentes acústicos relacionados ao ambiente.

As amostras digitalizadas de fala foram reproduzidas com fone de ouvido e analisadas perceptivo-auditivamente por três fonoaudiólogas especialistas em voz. As vozes foram classificadas segundo escala GRBASI para avaliação da disfonia ${ }^{(28,29)}$.
Esta escala envolve os seguintes parâmetros: grau geral de alteração $(\mathrm{G})$, rugosidade $(\mathrm{R})$, soprosidade $(\mathrm{B})$, astenia $(\mathrm{A})$, tensão $(\mathrm{S})$ e instabilidade (I), cada um com quatro graduações: 0 (sem alteração), 1 (alteração discreta), 2 (alteração moderada) e 3 (alteração extrema). Para a análise da qualidade vocal, embora avaliados todos os parâmetros, optou-se, neste estudo, por evidenciar dois valores da escala GRBASI: grau geral $(\mathrm{G})$ e tensão fonatória $(\mathrm{S})$.

O grau geral $(\mathrm{G})$ é o parâmetro da escala GRBASI que reflete o impacto global da voz, portanto foi destacado como um dos parâmetros de análise das vozes das professoras. Destacou-se também o parâmetro tensão (S) por ser o único cujas avaliações foram maiores do que 1 em $40 \%$ da amostra. Considerou-se, portanto, que a correlação entre este parâmetro (S) e o ruído ambiental poderia ser relevante.

\section{Procedimentos de análise de dados}

Após o levantamento dos dados obtidos foi realizada primeiramente a verificação da existência ou não da concordância entre os três juízes sobre cada um dos seis critérios referentes à qualidade vocal do professor, por meio da análise de concordância de Kappa. Posteriormente foram realizadas relações entre o nível de ruído ambiental, o nível de intensidade da voz e a qualidade vocal dos professores utilizando o Teste de Correlação de Pearson com nível de significância de 5\%. Pode-se assim mensurar o quanto as variáveis estão interligadas por valores percentuais positivos ou negativos. A correlação positiva significa que à medida que uma variável aumenta seu valor, a outra, correlacionada a esta, também aumenta. Porém, se a correlação for negativa, as variáveis são inversamente proporcionais, ou seja, à medida que uma cresce a outra decresce. Os resultados foram colocados em uma única tabela, chamada de Matriz de Correlação, na qual o resultado de correção foi expresso em porcentagem para facilitar a leitura e/ou entendimento da análise. 
Tabela 1. Valores médios de ruído ambiental e grau de alteração vocal das professoras

\begin{tabular}{|c|c|c|c|c|c|c|c|c|c|}
\hline \multirow[b]{2}{*}{ Salas } & \multicolumn{3}{|c|}{ Valores médios - $\mathrm{dB}(\mathrm{A})$} & \multicolumn{6}{|c|}{ GRBASI } \\
\hline & $\begin{array}{c}\text { Ruído sem } \\
\text { criança }\end{array}$ & $\begin{array}{l}\text { Ruído com } \\
\text { criança }\end{array}$ & $\begin{array}{l}\text { Intensidade } \\
\text { da voz das } \\
\text { professoras }\end{array}$ & $\begin{array}{l}\text { Grau geral } \\
(\mathrm{G})\end{array}$ & $\begin{array}{l}\text { Rugosidade } \\
\text { (R) }\end{array}$ & $\begin{array}{l}\text { Soprosidade } \\
\text { (B) }\end{array}$ & $\begin{array}{c}\text { Astenia } \\
\text { (A) }\end{array}$ & $\begin{array}{c}\text { Tensão } \\
\text { (S) }\end{array}$ & $\begin{array}{c}\text { Instabilidade } \\
\text { (I) }\end{array}$ \\
\hline 1 & 44,79 & 45,06 & 52,54 & 2 & 1 & 0 & 0 & 2 & 1 \\
\hline 2 & 44,8 & 56,05 & 60,00 & 2 & 1 & 0 & 0 & 2 & 1 \\
\hline 3 & 44,61 & 55,88 & 62,64 & 2 & 0 & 0 & 0 & 2 & 0 \\
\hline 4 & 45,83 & 60,77 & 62,07 & 0 & 0 & 0 & 0 & 1 & 0 \\
\hline 5 & 51,52 & 63,17 & 68,43 & 1 & 1 & 1 & 0 & 1 & 0 \\
\hline 6 & 41,6 & 52,03 & 59,76 & 2 & 1 & 1 & 0 & 0 & 0 \\
\hline 7 & 56,44 & 56,55 & 60,00 & 0 & 1 & 0 & 0 & 1 & 0 \\
\hline 8 & 40,66 & 64,16 & 64,73 & 2 & 1 & 0 & 0 & 2 & 1 \\
\hline 9 & 45,22 & 63,73 & 64,25 & 0 & 0 & 0 & 0 & 1 & 0 \\
\hline 10 & 45,31 & 65,02 & 62,53 & 1 & 1 & 0 & 0 & 1 & 1 \\
\hline Média & 46,08 & 58,24 & 61,70 & & & & & & \\
\hline
\end{tabular}

\section{RESULTADOS}

A análise dos juízes sobre a qualidade vocal foi altamente concordante em todos os itens, sendo que o menor valor obtido foi de 0,86 . O ruído ambiental das salas de aula, na ausência dos alunos, variou de 40,6 a 50,6 dB(A), sendo o valor médio das 10 salas de aulas 46,08 dB(A). Do total, $20 \%$ das salas (5 e 7) apresentaram NPS de ruído acima de $50 \mathrm{~dB}(\mathrm{~A})$ (Tabela 1). Na presença dos alunos, o NPS de ruído aumentou, variando de 45,06 a 65,02 $\mathrm{dB}(\mathrm{A})$, com valor médio de 58,24 $\mathrm{dB}(\mathrm{A})$. Nove das 10 salas $(90 \%)$ apresentaram níveis superiores ao recomendado pela Norma Brasileira NBR $10152^{(1)}$, chegando a mais de $20 \mathrm{~dB}(\mathrm{~A})$ na sala 8 (Tabela 1 ).

Os níveis de pressão sonora (NPS) da voz das professoras variaram entre $52 \mathrm{~dB}(\mathrm{~A})$ e $68 \mathrm{~dB}(\mathrm{~A})$, chegando a 7,48 $\mathrm{dB}(\mathrm{A})$ acima do ruído ambiental que foi medido durante as aulas. Os dados da avaliação perceptivo-auditiva da voz das professoras mostraram que $50 \%$ delas apresentaram grau moderado de alteração vocal $\left(G_{2}\right)$ e $20 \%$ grau discreto $\left(G_{1}\right)$. A tensão vocal foi constatada na maior parte das professoras, sendo $50 \%$ em grau discreto e $40 \%$ moderado (Tabela 1).

Foi realizada a relação entre os valores médios do nível de pressão sonora das vozes das professoras e do ruído ambiental (NPS), com e sem crianças (Figura 1). Ainda que as medições tenham ocorrido em momentos distintos constatou-se correlação positiva entre intensidade vocal e ruído ambiental durante as aulas com a presença das crianças (Tabela 2 e Figura 1).

Tabela 2. Matriz de correlação entre intensidade vocal e ruído ambiental

\begin{tabular}{llc}
\hline & & $\begin{array}{c}\text { Ruído ambiental } \\
\text { com crianças }\end{array}$ \\
\hline $\begin{array}{l}\text { Ruído ambiental sem } \\
\text { crianças }\end{array}$ & Correlação & $6,7 \%$ \\
\hline Intensidade da voz das & Calor de $\mathrm{p}$ & 0,855 \\
professoras durante a aula & Valor de $\mathrm{p}$ & $87,2 \%$ \\
\hline
\end{tabular}

*Valores significativos $(p<0,05)$ - Teste de Correlação de Pearson

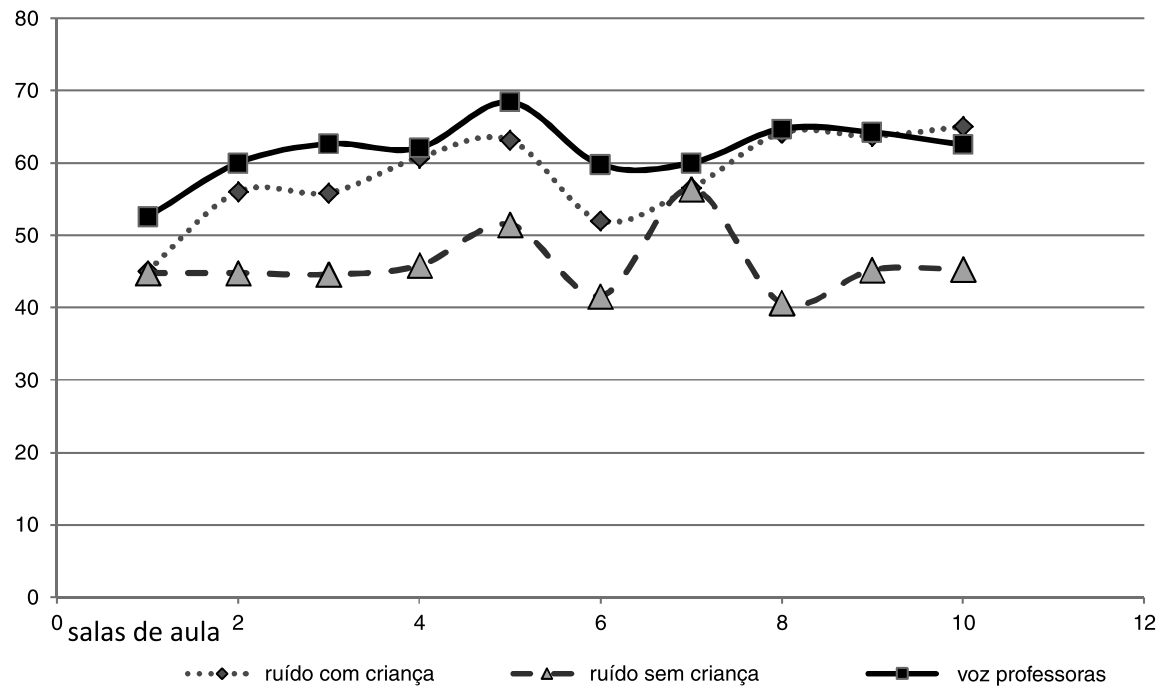

Figura 1. Distribuição dos valores de ruído em sala de aula e intensidade vocal das professoras 
Não foram constatadas correlações positivas entre os dados de qualidade vocal das professoras e as variáveis referentes ao ruído (NPS) das salas de aula e à intensidade vocal das vozes (NPS) (Tabela 3).

Tabela 3. Matriz de correlação entre ruído ambiental, intensidade de voz, grau geral de alteração e tensão vocal

\begin{tabular}{llcc}
\hline & & $G(\geq 1)$ & $S(\geq 1)$ \\
\hline Ruído da classe & Correlação & $-46,1 \%$ & $-14,4 \%$ \\
com criança & Valor de $p$ & 0,180 & 0,691 \\
\hline Intensidade da & Correlação & $-29,1 \%$ & $-19,5 \%$ \\
voz da professora & Valor de p & 0,414 & 0,589 \\
\hline
\end{tabular}

Teste de Correlação de Pearson $(p<0,05)$

Legenda: $\mathrm{G}$ = grau geral de alteração de voz; $\mathrm{S}$ = tensão vocal

\section{DISCUSSÃO}

O presente estudo avaliou todas as dez classes do primeiro ano do ensino fundamental da cidade. Embora o número possa ser considerado pequeno, como em alguns outros trabalhos da literatura ${ }^{(6,8)}$, esta pesquisa traz dados peculiares de uma rede de ensino no interior do estado de São Paulo.

No que diz respeito ao ruído ambiental, nas duas situações estudadas pode-se destacar que a presença dos alunos eleva os níveis de ruído. A observação no local revelou a multifatoriedade de fontes sonoras em sala de aula, como conversas e inquietudes entre os alunos, barulho dos ventiladores ligados durante a aula, movimentação de pessoas nos corredores, no pátio e nas outras salas durante o horário letivo. Esses fatores contribuem para o ruído ambiental em situação de sala de aula expondo o aluno a diversos estímulos além da voz do professor $^{(4,5)}$, originando processos de desatenção. Isso ocorreu principalmente nas salas 1 e 3 .

As salas 5 e 7 foram as que apresentaram valores médios de maior nível (NPS) de ruído ambiental sem a presença dos alunos, embora não tenham sido as mais ruidosas com a presença deles. Provavelmente nestas salas ocorrem estratégias diferenciadas de atenção por parte das crianças para conseguir escutar a professora, mesmo na presença do ruído ambiental mais intenso ${ }^{(4)}$. Por outro lado pode ser que a professora exerça maior controle sobre os alunos, buscando favorecer a atenção em sala de aula e uma atitude mais ativa no processo de aprender ${ }^{(21)}$, focando sua voz como recurso no processo de aprendizagem $^{(19)}$.

Os resultados referentes aos valores médios do ruído ambiental foram semelhantes aos obtidos em estudos anteriores realizados no interior das salas de aula, nos quais foram constatados níveis elevados de ruído que variaram de $56 \mathrm{~dB}$ (A) a 94,1 $\mathrm{dB}(\mathrm{A})^{(5,16,24)}$. Em decorrência disso, há sugestão para que estas salas de aulas investigadas tenham uma atenção preventiva dos gestores para minimizar o desconforto e favorecer condições ideais de ensino-aprendizagem.

A maioria das professoras investigadas compete com o ruído numa relação positiva para o sinal de fala de até 7,73 dB(A). Não encontramos outros estudos que tenham utilizado o mesmo método para realizarmos uma comparação, mas algumas considerações são pertinentes. Primeiro, o valor positivo aqui apresentado, de 7,73 $\mathrm{dB}(\mathrm{A})$, é superior ao encontrado em outro estudo ${ }^{(24)}$. Entretanto, neste último, a intensidade da voz do professor foi obtida em uma silenciosa, e não in loco. Outro aspecto diz respeito à escassez de estudos com este tipo de proposta. Em 15 anos de publicações brasileiras sobre voz do professor somente $1,9 \%$ dos estudos foram realizados no interior da sala de aula, sendo que nenhum deles abordou a mensuração do nível de ruído da sala ou da intensidade vocal do professor durante o exercício profissional ${ }^{(30)}$. Pode-se aventar que a dificuldade quanto ao método de mensuração da intensidade vocal in loco é uma barreira a ser transposta para a realização deste modelo de estudo, uma vez que a obtenção do registro vocal é complexa.

No presente estudo, o nível de pressão sonora (NPS) das vozes das professoras foi medido em combinação com NPS do ruído de fundo durante a aula. No entanto, o direcionamento do microfone a um metro do professor e o registro com maior intensidade do que o de ruído de fundo nos leva a considerar que a intensidade vocal do professor não foi mascarada, embora seja provável que possa ter interferido em algum grau na estimativa das correlações.

Finalmente, embora a correlação entre o nível de ruído e a intensidade da voz do professor tenha sido positiva, ou seja, quanto maior o nível de ruído, maior a intensidade da voz do professor; isso não foi insuficiente para que o professor fosse ouvido de forma clara pelos alunos. Para tanto, a voz do professor deveria ter no mínimo $10 \mathrm{~dB}(\mathrm{~A})$ a mais que o nível de ruído ambiental ${ }^{(20)}$.

Neste contexto, os resultados sobre a elevação da voz das professoras abaixo do nível necessário para favorecer a compreensão dos alunos sugerem diversas possibilidades para justificá-los. Uma das possibilidades é a dificuldade em se estabelecer uma relação entre voz alterada e ruído devido ao fato de se ter um grupo muito grande com alteração de voz dentro da amostra, o que dificulta qualquer correlação. Outra é a suposição de que as professoras possuam ciência de que não conseguem competir com o ruído, por este motivo não elevam a voz suficientemente para criar a relação positiva necessária, comportamento esse que visaria à saúde vocal. Também, pode-se considerar a possibilidade de que as professoras da amostra não conseguem elevar a voz em resposta à elevação do ruído ambiental ${ }^{(7,10,26)}$ em decorrência de dificuldades fonatórias merecedoras de investigação mais aprofundada, prevenindo assim o desenvolvimento de uma disfonia mais intensa durante o exercício profissional ${ }^{(11)}$.

Sabe-se que competição da voz com o ruído ambiental favorece a presença de esforço intenso para se fazer ouvir ${ }^{(6)}$. O uso dessa estratégia é discutido por pesquisadores na busca de soluções que possibilitem um ambiente acústico mais saudável favorecendo as condições de ensino-aprendizagem. Além dos professores, os alunos também sofrem com a presença do ruído, apresentando dificuldades em manter a atenção, o que pode resultar em baixo rendimento escolar ${ }^{(3,6,7,9,15)}$.

Foi observada correlação positiva entre a intensidade da voz das professoras e o ruído durante a aula com presença dos alunos, corroborando dados de diversos estudos ${ }^{(5,7,13,19,28)}$. Reportando esta correlação ao contexto escolar, leva-se à suposição de que quanto maior o ruído em sala com o aluno, 
maior a intensidade (NPS) da voz do professor e vice-versa. Os dados positivos sobre o assunto têm sido observados com atenção na tentativa de estabelecer relação causal com o surgimento de alterações vocais entre professores, pois falar em alta intensidade com frequência pode trazer danos às pregas vocais e rouquidão em diversos graus. Assim, tem-se um forte indicativo da necessidade das professoras deste estudo serem orientadas no sentido de minimizar o ruído da sala de aula e, consequentemente, evitar o uso vocal em intensidades muito elevadas que geram desgaste da $\mathrm{voz}^{(7)}$.

Como em outros estudos ${ }^{(14,20,25)}$ constatamos alta ocorrência de alterações vocais (70\%), sendo a maioria em grau moderado. A presença de tensão fonatória em $90 \%$ da amostra que este é um dos parâmetros mais frequentes entre os professores ${ }^{(20)}$. Tais dados sugerem que essas professoras, como profissionais que utilizam a voz como recurso de trabalho devem realizar avaliação vocal periodicamente.

Não foi possível estabelecer correlações entre qualidade de voz (presença de alteração de voz) e ruído ambiental, tal qual ocorreu em estudo recente ${ }^{(16)}$ que investigou 27 professores de diferentes escolas da cidade de São Paulo. No presente estudo, identificamos somente que as variáveis são inversamente proporcionais. Desta forma, os resultados obtidos com esta amostra não confirmam a hipótese levantada em muitas publicações $^{(7,11,13,15,25)}$ de que a presença de ruído ambiental estaria relacionada à presença de vozes alteradas entre professores.
Deve-se destacar que as condições de medição do nível de pressão sonora e o tipo de microfone utilizado possam ter trazido vieses nas correlações obtidas, e também considerar que nos estudos supracitados, os dados foram obtidos por protocolos de autoavaliação e não por amostra vocal com posterior análise perceptivo-auditiva de especialistas. Nesse sentido, reforça-se a necessidade da realização de novos estudos sobre as relações de causa-efeito entre ruído e alteração vocal.

\section{CONCLUSÃO}

Os resultados obtidos neste estudo revelam altos níveis de ruído ambiental em sala de aula e correlações positivas entre tais valores e a intensidade vocal das professoras. É alta ocorrência de vozes alteradas, mas não é possível correlaciona-la aos níveis de ruído ambiental.

\section{AGRADECIMENTOS}

Nossos agradecimentos aos gestores e professores da Rede Municipal de Ensino que nos autorizaram e consentiram o desenvolvimento deste estudo; e ao apoio do Conselho Nacional de Desenvolvimento Científico e Tecnológico (CNPq), por meio do Programa Institucional de Bolsas de Iniciação Científica (PIBIC) do Centro Universitário de Araraquara - UNIARA - Araraquara (SP), Brasil (processo ${ }^{\circ} 113892 / 2008-0$ ).

\begin{abstract}
Purpose: To explore the existence of correlations between environmental noise in classrooms, voice intensity and teacher's vocal problems. Methods: Environmental noise was measured in 10 classrooms of municipal elementary schools; the intensity of teachers' voice was measured during teaching practice; teachers' speech samples containing emissions of sustained vowel [é] and counting from 1 to 20 were analyzed using the GRBASI protocol; and the results were tested for correlation. Results: The average of environmental noise varied from 40 to $51 \mathrm{~dB}(\mathrm{~A})$ without the presence of children in the classroom, and from 45 to $65 \mathrm{~dB}(\mathrm{~A})$ with the presence of children. Among teachers, there was $70 \%$ of vocal problems $(\mathrm{G})$ and $90 \%$ of vocal strain (S) varying from moderate to mild degrees. The intensity of teachers' voice varied from $52 \mathrm{~dB}(\mathrm{~A})$ to $68 \mathrm{~dB}(\mathrm{~A})$, reaching $7.48 \mathrm{~dB}(\mathrm{~A})$ above the environmental noise. There was a significant correlation between the intensity of teachers' voice and the environmental noise during the class in the presence of children. Conclusion: There were high levels of environmental noise in the classrooms, which correlated with the intensity of teachers' voice (SPL). Although there was high occurrence of vocal problems in this sample, they were not correlated with the level of environmental noise.
\end{abstract}

Keywords: Voice; Noise; Faculty; Dysphonia; Auditory perception

\title{
REFERÊNCIAS
}

1. ABNT- Associação Brasileira de Normas Técnicas. NBR 10152: Níveis de ruído para conforto acústico. Rio de Janeiro, 2000.

2. Nunes MF, Sattler MA. Percepção do ruído aeronáutico em Escolas da zona Ido PEZR do aeroporto internacional Salgado Filho. Engevista. 2005; 6(3):5-24.

3. Pereira TC, Silva IB, Coutinho AS, Oiticica ML. Análise das condições acústicas em sala de aula climatizada de ambiente universitário. XXIV Encontro Nacional de Engenharia de Produção. 2004. Florianópolis.

4. Dreossi RC, Momensohn-Santos T. O Ruído e sua interferência sobre estudantes em uma sala de aula: revisão de literatura. Pró-Fono. 2005;17(2): 251-8.
5. Jaroszewski GC, Zeigelboim BS, Lacerda A. Ruído escolar e sua implicação na atividade de ditado. Rev CEFAC; 2007;9(1):122-32.

6. Batista JB, Carlotto MS, Coutinho AS, Pereira DA, Augusto LG. O ambiente que adoece: condições ambientais de trabalho do professor do ensino fundamental. Cad Saúde Colet. 2010;18(2):234-42.

7. Behlau M, Dragone ML, Nagano L. A voz que ensina: o professor e a comunicação oral em sala de aula. Rio de Janeiro: Revinter; 2004.

8. Libardi A, Gonçalves GO, Vieira TP, Silverio KC, Rossi D, Penteado RZ. O ruído em sala de aula e a percepção dos professores de uma escola de ensino fundamental de Piracicaba. Distúrb Comum. 2006;18(2):167-78. 
9. Jardim R, Barreto SM, Assunção AA. Condições de trabalho, qualidade de vida e disfonia entre docentes. Cad Saúde Pública. 2007;23(10):243946.

10. Behlau M, Zambon F, Guerrieri AC, Roy N. Panorama epidemiológico sobre a voz do professor no Brasil. Rev Soc Bras Fonoaudiol. 2009:14 (supl.): 1511.

11. Luchesi KF, Mourão LF, Kitamura S. Problemas vocais no trabalho: prevenção na prática docente sob a óptica do professor. Saúde Soc [online]. 2009;18(4):673-81.

12. Roy N, Merril RM, Thibeault S, Parsa RA, Gray SD, Smith EM. Prevalence of voice disorders in teachers and the general population. J Speech Lang Hear Res. 2004;47(2):281-93.

13. Simões L, Latorre MR. Prevalência de alteração vocal em educadoras e sua relação com a auto-percepção. Rev Saúde Pública. 2006;40(6):10138.

14. Leite MP, Souza NA. Condições do trabalho e suas repercussões na saúde dos professores da educação básica no Brasil - Estado da Arte. Campinas: FUNCAMP; 2007.

15. Penteado RZ, Pereira IM. Qualidade de vida e saúde vocal dos professores. Rev Saúde Pública. 2007:41(2): 236-43.

16. Simões-Zenari M, Bitar ML, Nemr K. Voz de educadoras: relações entre auto-avaliação vocal, aspectos perceptivos auditivos e acústicos e níveis de ruído. Rev Soc Bras Fonoaudiol. 2009:14(supl.):1477.

17. Alves LA, Rambazzi ML, Marziali ML, Felippe AC, Romano CC. Health disorders and teachers' voices: a workers' health issue. Rev Latino-Am Enfermagem. 2009;17(4):566-72.

18. Tapia JA. Contexto, motivação e aprendizagem. In: Tapia JA, Fita EC. A motivação em sala de aula. São Paulo: Loyola; 2004.

19. Gonçalvez CG, Penteado RZ, Silvério KC. Fonoaudiologia e Saúde do Trabalhador: a questão da saúde vocal do professor. Saúde em Revista. 2005;7(15):45-51

20. Silvério KC, Gonçalvez CG, Penteado RZ, Vieira TP, Libardi A, Rossi D. Ações em saúde vocal: proposta de melhoria do perfil vocal de professores. Pró-Fono. 2008;20(3):177-82.
21. Azevedo LL, Vianello L, Oliveira LG, Oliveira IA, Oliveira BF, Silva CM. Queixas vocais e grau de disfonia em professoras do ensino fundamental. Rev Soc Bras Fonoaudiol. 2009;14(2):192-6.

22. Giannini SP, Ferreira LP, Passos MC. Histórias que fazem sentidos: as determinações das alterações vocais do professor. Distúrb Comum. 2006;18(2):245-57.

23. Dragone ML, Behlau M. A Fonoaudiologia Brasileira e a voz do professor: olhares científicos no decorrer do tempo. Rev Soc Bras Fonoaudiol. 2006;4(2):6-9.

24. Gonçalves VS, Silva LB, Coutinho AS. Ruído como agente comprometedor da inteligibilidade de fala dos professores. Produção. 2009;19(3):466-76.

25. Servilha EA, Ruela IS. Riscos ocupacionais à saúde e voz de professores: especificidades das Unidades de Rede Municipal de Ensino. Revista CEFAC. 2010;12(1):109-14.

26. Lindstrom F, Persson Waye K, Södersten M, MacAllister A, Ternström S. Observations of the relationship between noise exposure and preschool teacher voice usage in day-care center environments. J Voice. 2011;25(2):166-72.

27. ABNT: Associação Brasileira de Normas Técnicas. NBR 10151: Acústica: avaliação do ruído em áreas habitadas, visando o conforto da comunidade: procedimento. Rio de Janeiro; 2000.

28. Hirano M. Clinical examination of voice. New York: Springer Verlag; 1981. p. 81-4.

29. Dejonckere P, Remacle M, Freznel-Elbaz E. Reliability and relevance of differentiated perceptual evaluation of pathological voice quality. In: Clemente MP. Voice Update. Amsterdan: Elsevier; 1996. p. 321-4.

30. Dragone ML, Ferreira LP, Giannini SP, Simões-Zenari M, Vieira VP, Behlau M. Voz do professor: uma revisão de 15 anos de contribuição fonoaudiológica. Rev Soc Bras Fonoaudiol. 2010;16(2):289-96. 